\title{
MODELO EXPERIMENTAL DE CARCINOGÊNESE ESOFÁGICA
}

\author{
EXPERIMENTAL MODEL OF ESOPHAGEAL CARCINOGENESIS
}

\author{
Miguel Angelo Martins de Castro Junior, TCBC-RS ${ }^{1}$; Cleber Dario Pinto Kruel, TCBC-RS²; \\ Luize Meurer ${ }^{3}$; Angela Pötter de Castro ${ }^{4}$; Bruno Sudbrack Zimmermann
}

\begin{abstract}
RESUMO: Objetivo: O carcinoma epidermóide do esôfago é neoplasia com alta taxa de mortalidade. A necessidade do entendimento do processo de carcinogênse na melhora de resultados desta doença, conduz aos estudos experimentais. Método: Induzida a carcinogênese esofágica quimicamente por meio da dietilnitrosamina(DEN), em um grupo de 100 camundongos fêmeas. Utilizados quatro grupos, onde os Grupos 1 e 2 foram considerados controles, sendo diferenciados por gavagem esofágica, uma vez semana, com água em temperatura ambiente $\left(20-25^{\circ} \mathrm{C}\right)$ ou quente $\left(60^{\circ}-70^{\circ} \mathrm{C}\right)$. E os Grupos 3 e 4 , considerados estudos, receberam DEN por três dias consecutivos semanalmente, também sendo diferenciados por gavagem quente ou fria. Progressivas eutanásias com coletas de peças esofágicas, com início no $30^{\circ}$ dia do experimento e terminando no $150^{\circ}$ dia. Resultados: Demonstrou-se que não houve diferença na incidência tumoral quando foi acrescida a variável temperatura da água $(\mathrm{p}=0,6854)$. Observou-se, que a carcinogênese durante o experimento, considerados os grupos que receberam DEN como sendo um único grupo, demonstrou clara e evidente progressão de lesões neoplásicas. Conclusão: Houve progressão neoplásica esofágica com a utilização de DEN, bem como o método pode ser utilizado em estudos para investigação do processo mutagênico (Rev. Col. Bras. Cir. 2007; 34(3): 153-156).
\end{abstract}

Descritores: Marcadores de biológicos de tumor; Esôfago; Carcinoma de células escamosas; Dietilnitrosamina.

\section{INTRODUÇÃO}

O câncer de esôfago está associado a baixos índices de sobrevida. É um dos dez tumores sólidos mais freqüentes mundialmente, com característica variação geográfica em relação à sua incidência. O carcinoma epidermóide é um dos dois tipos histológicos primários de esôfago responsáveis por $95 \%$ dos casos ${ }^{1}$.

Sendo a sobrevida geral do portador, pouco influenciada por modalidades terapêuticas, como ressecção cirúrgica, associada ou não à quimioterapia neoadjuvante e à radioquimioterapia adjuvante, questiona-se que a população de doentes apresente características diferentes, havendo outros fatores não valorizados ${ }^{2,3}$, que influenciem o prognóstico ${ }^{4}$.

A análise da célula tumoral, ou de suas diferenciações celulares pré-tumorais, demonstrou haver por análise imuno-histoquímica e genética ${ }^{5}$ determinantes que podem ajudar o diagnóstico precoce, o prognóstico, a detecção de metástase oculta, e a quimiorresistência ${ }^{6,7}$. Esses, denominados marcadores tumorais, são produtos (proteínas) quer de alterações de genes, quer de proliferação celular aumentada, entre outros.

A necessidade de avaliação deles por amostras de intervenções cirúrgicas ou autópsias, por muitas razões, não responde completamente a vários determinantes. Modelos experimentais tornam-se a opção, pela reprodutibilidade, com número significativo de lesões e principalmente pela possibilidade de acompanhamento e entendimento do processo de carcinogênese.

\section{MÉTODO}

O trabalho foi realizado na Unidade de Experimentação Animal, do Centro de Pesquisa do Hospital de Clínicas de Porto Alegre, após aprovação pela Comissão Científica e pela Comissão de Pesquisa e Ética em Saúde, do Hospital de Clínicas de Porto Alegre.

Foram utilizados camundongos ("Mus musculus", cepa CF1), num total de 100 fêmeas, com 60 dias de vida. Mantidos em condições estáveis de umidade, temperatura, fluxo contínuo de ar, ciclo de 12 horas de claro e escuro, e adaptados por sete dias. Foram supridas as necessidades básicas de alimentação e conforto em consonância com os preceitos da literatura ${ }^{8}$.

Adotou-se a dietilnitrosamina (DEN) para carcinogênese química, a qual é substância química do grupo das nitrosaminas (C4H10N20) ${ }^{9}$. Carcinógeno completo, produzindo indução e promoção tumoral. Administrada na água de beber, na concentração de $0,04 \mathrm{mg} / 1000 \mathrm{ml}$.

1. Professor Assistente do Departamento de Cirurgia da Fundação Universidade Federal de Rio Grande - FURG

2. Professor do Departamento de Cirurgia da Universidade Federal do Rio Grande do Sul - UFRGS.

3. Médica Patologista do Hospital de Clínicas de Porto Alegre; Doutora em Medicina pela Universidade Federal do Rio Grande do Sul - UFRGS.

4. Professora Substituta do Departamento de Cirurgia da Fundação Universidade Federal de Rio Grande; Mestre pela Universidade Federal do Rio Grande do Sul - UFRGS.

5. Acadêmico de Medicina.

Recebido em 03/11/2006

Aceito para publicação 06/01/2007

Conflito de interesses: nenhuma

Fonte de financiamento: nenhuma

Trabalho realizado na Pós-Graduação em Ciências em Gastroenterologia; Unidade de Experimentação Animal do Centro de Pesquisa do Hospital de Clínicas de Porto Alegre, Universidade Federal do Rio Grande do Sul - UFRGS. 
Os animais foram distribuidos em quatro Grupos da seguinte forma:

- Grupo $1(\mathrm{n}=10)$ recebeu água ad libitum e gavagem esofágica uma vez por semana com água fria $\left(25^{\circ} \mathrm{C}\right)$.

- Grupo $2(\mathrm{n}=10)$ recebeu água ad libitum e gavagem uma vez por semana com água quente $\left(60^{\circ}-70^{\circ} \mathrm{C}\right)$.

- Grupo $3(\mathrm{n}=40)$ recebeu água ad libitum de sextas a terças-feiras, substituída por DEN, que permanecia por 72 horas seguintes; e gavagem uma vez por semana com água fria.

- Grupo $4(n=40)$ recebeu água ad libitum de sextas a terças-feiras, substituída por DEN, que permanecia por 72 horas seguintes; e gavagem uma vez por semana com água quente.

A gavagem esofágica foi realizada semanalmente durante todo o estudo com duração não maior que 30 segundos, exclusivamente nos dias em que os animais recebiam apenas água.

Os animais foram ao óbito e então coletados espécimes esofágicos conforme esquema:

- Grupo Controle: Eutanásia da metade da amostra do Grupo 1 e 2 no $30^{\circ}$ dia de experimento e cinco restantes da amostra no $150^{\circ}$ dia.

- Grupo Estudo: Eutanásia de cinco animais de cada amostra dos Grupos 3 e 4 no $30^{\circ}, 60^{\circ}, 90^{\circ}, 120^{\circ}$ dia de experimento, e dos 20 animais restantes dos grupos no $150^{\circ}$ dia nos quais era feita a contagem do número de tumores, sendo adotado como ponto de corte lesões superiores a $1 \mathrm{~mm}$.

Os esôfagos retirados foram submetidos ao exame histológico por técnica previamente descrita e os achados foram classificados conforme a literatura ${ }^{10}$.

Realizada análise descritiva e teste " $t$ " para diferença entre proporções.

\section{RESULTADOS}

Houve três óbitos, sendo todos do Grupo 4: dois precoces, relacionados à aspiração pulmonar pela gavagem e outro tardio, relacionado à debilidade física.

Não foram evidenciadas, conforme descrito previamente ${ }^{11-14}$, presença à necropsia de tumorações em outras localizações de fácil identificação macroscópica.

Não foram detectadas alterações patológicas nos Grupos 1 e 2, cujos esôfagos serviram de padrão de normalidade.

Não houve diferença relevante nas características macroscópicas dos tumores nos grupos estudos e, embora não tenham sido objeto especial de atenção, variações na forma e dimensões dos tumores foram comuns aos Grupos 3 e 4, assim como multiplicidade.

O número de tumores, contados no grupo estudo no $150^{\circ}$ dia de experimento, foi maior no Grupo 4, com 13 tumores em 17 peças esofágicas, seguido do Grupo 3, com 14 tumores em 20 peças esofágicas. Estes achados não alcançaram diferença estatística $(\mathrm{p}=0,6854)$. Não houve, por este resultado, diferença entre os grupos que receberam DEN com variação entre gavagem com água quente ou fria.

As figuras 1, 2 e 3 demonstram a evolução anatomopatológica durante o experimento.

\section{Achados Anatomopatológicos - Água Fria}

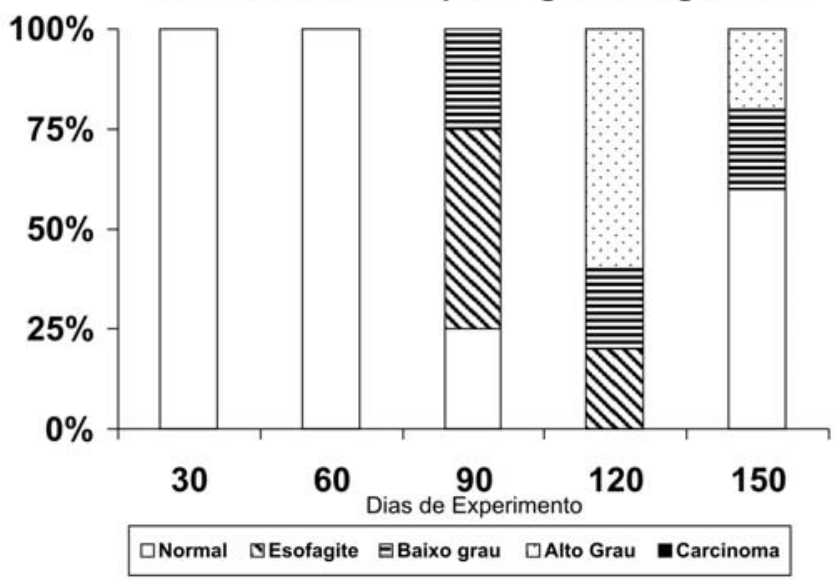

Figura 1 - Distribuição de resultados de anatomia patológica durante o experimento nos animais que receberam administração complementar de água fria por gavagem (com DEN).

\section{Achados Anatomopatológicos - Água Quente}

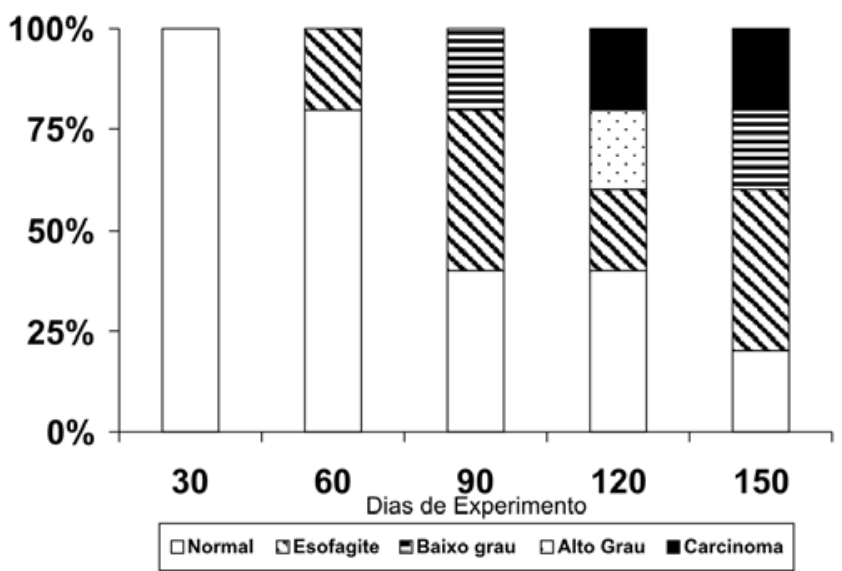

Figura 2 - Distribuição de resultados de anatomia patológica durante o experimento nos animais que receberam administração complementar de água quente por gavagem (com DEN).

Achados Anatomopatológicos - DEN Geral

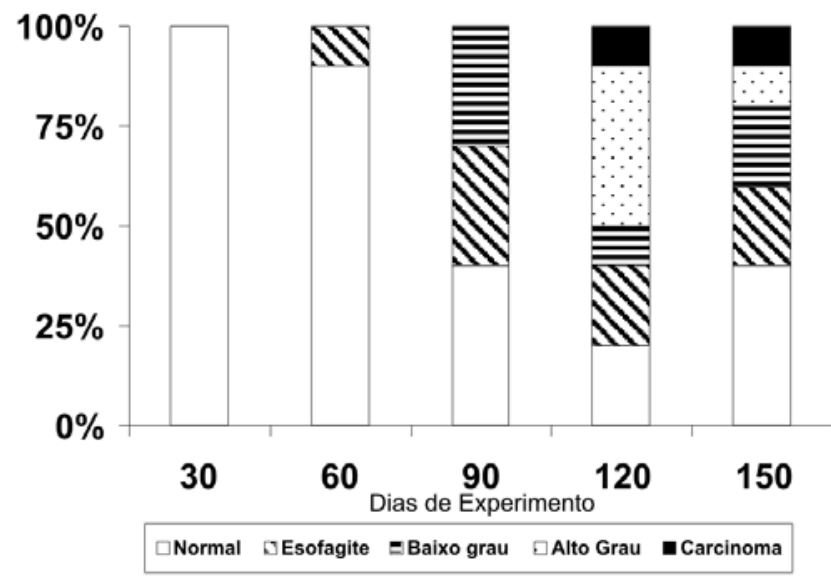

Figura 3 - Distribuição de resultados de anatomia patológica durante o experimento nos animais que receberam DEN independente do tipo de gavagem. 


\section{DISCUSSÃO}

Foram utilizadas fêmeas por ser conhecida a morte de animais por conflitos territoriais, atitude quase exclusiva dos machos ${ }^{11}$. Essas perdas, associadas às naturais, às relacionadas à toxicidade e ao efeito carcinógeno da DEN, que levam ao comprometimento progressivo das condições gerais, poderiam comprometer a pesquisa.

Os tempos para a eutanásia foram escolhidos em função do conhecimento prévio ${ }^{11,15}$ de aparecimento de tumores em torno do $120^{\circ}$ dia após início da ingestão do carcinógeno. Ao $30^{\circ}$ dia, ocorrem modificações do tipo esofagite, as primeiras lesões intraepiteliais nos $60^{\circ}-90^{\circ}$ dias e os primeiros carcinomas no $120^{\circ}$ dia. O percentual de carcinoma invasor foi 9,5 no $150^{\circ}$ dia e 26,5 no $180^{\circ}$ dia no trabalho de Kruel ${ }^{11}$. Dessa forma, o experimento acompanhou a cronologia da histogênese do carcinoma escamoso esofágico. Kruel ${ }^{11}$ demonstra o primeiro carcinoma invasor no T120, dois outros no T150 e outros 26 no T180, evidenciando uma clara eclosão de tumores a partir de $\mathrm{T} 150$.

Contrariando os achados prévios ${ }^{16,17}$, a administração de água quente, tanto nos animais do grupo controle (Grupo 2), como, principalmente, nos animais no grupo estudo (Grupo 4), não apresentou variação estatística aos resultados de seus grupos pares (Grupo 1 e 3, respectivamente). Este achado contraria os achados nesses trabalhos como em outros isto é, que a ação térmica promove o aparecimento precoce e o comportamento mais agressivo das lesões expansivas neoplásicas esofágicas. Talvez este achado possa ser justificado pelo "n" de cada amostra ser pequeno, proporcionalmente à divisão entre os grupos, ou ainda pela administração única apenas semanal, trazendo pouco efeito térmico esofágico. O composto nitroso, utilizado nos trabalhos citados, foi diferente ao que foi disponibilizado aos animais neste trabalho.

Observou-se que a carcinogênese, durante o experimento, considerados os grupos que receberam dietilnitrosamina como sendo um único grupo (figura 3), demonstrou clara e evidente progressão de lesões patológicas que culminaram com formação de casos de carcinoma, a partir do tempo 120 dias. Tal evolução demonstrada pode ser utilizada em estudos futuros para investigação de marcadores tumorais, bem como para entendimento molecular e genético deste detalhado processo mutagênico.

O método utilizado demonstrou-se factível bem como de baixo custo e com a principal vantagem de permitir estudo da carcinogênese esofágica em menos de 20 semanas de acompanhamento. Não foi demonstrada influência térmica nesse processo, quando utilizado o carcinógeno dietilnitrosamina, com esta metodologia.

\begin{abstract}
Background: Esophageal epidermoid carcinoma is a neoplasm with high mortality rates and a peculiar geographic distribution. Experimental studies are necessary to better understand the carcinogenesis process and improve therapeutic protocols. Methods: Esophageal carcinogenesis has been chemically induced with diethylnitrosamine (DEN) in 100 female mices. Four groups of animals were separated. Control groups I and II were treated weekly by esophageal gavage at room temperature or hot $\left(60^{\circ}-70^{\circ} \mathrm{C}\right)$ water. Study groups III and IV were treated weekly for 3 consecutive days with diethylnitrosamine receiving also esophageal gavage with room temperature or hot water. Mices were sequentially sacrificed from day 30 until day 150 for collection and analysis of the esophagus. Results: Results showed tumor incidence has not been affected by water temperature used for gavage ( $p=0.6854)$. Carcinogenesis has been induced in both groups receiving DEN, with clear and evident progression of pathological lesions. Conclusion: The model can be used for the study of mutagenic processes.
\end{abstract}

Key words: Tumor markers, biological ; Esophagus;Carcionoma, squamous cell; Diethylnitrosamine.

\section{REFERÊNCIAS}

1. Souza RF. Molecular and biologic basis of upper gastrointestinal malignancy - esophageal carcinoma. Surg Oncol Clin NAm. 2002; 11(2):257-72.

2. Casson AG, Evans SC, Gillis A, Porter GA, Veugelers P, Darnton SJ, Guernsey DL, Hainaut P. Clinical Implications of p53 tumor suppressor gene mutation and protein expression in esophageal adenocarcinomas: results of a ten-year prospective study. J Thorac Cardiovasc Surg. 2003; 125(5):1121-31.

3. Dolan K, Walker SJ, Gosney J, Field JK, Sutton R. TP53 mutations in malignant and premalignant Barrett's esophagus. Dis Esophagus. 2003; 16(2):83-9.

4. Koide N, Nishio A, Hiraguri M, Hanazaki K, Adachi W, Amano J. Coexpression of vascular endothelial growth factor and p53 protein in squamous cell carcinoma of the esophagus. Am J Gastroenterol. 2001; 96(6):1733-40.
5. Lehrbach DM, Nita ME, Cecconello I. Clinical Genomics of Esophageal Cancer Group. Molecular aspects of esophgeal saquamous cell carcinoma carcinogenesis. Arq Gastroenterol. 2003; 40(4):256-61.

6. Inada S, Koto T, Futami K, Arima S, Iwashita A. Evaluation of malignancy and the prognosis of esophageal cancer based on an immunohistochemical study (p53, E-cadherin, epidermal growth factor receptor). Surg Today. 1999; 29(6):493-503.

7. Lam KY, Law S, Ma LT, Ong SK, Wong J. Pre-operative chemotherapy for squamous cell carcinoma of the oesophagus: do histological assessment and p53 overexpression predict chemoresponsiveness? Eur J Cancer. 1997; 33(8):1221-5.

8. National Institutes of Health (NIRC). Guide for the care and use of laboratory animals. National Research Council. Washington, D.C.: National Academy Press; 1996.

9. IARC monographs on the evaluation of the carcinogenic risk of chemicals to humans: some N-nitroso compounds. IARC Monogr Eval Carcinog Risk Chem Man. 1978; 17:1-349. 
10. WHO. Histological typing of gastric and oesophageal tumors. International histological Classification of Tumors. 18. Genova: World Health Organization; 1977.

11. Kruel CDP, Pan Chacon J. Classificação citopatológica das lesões precursoras do carcinoma escamoso do esôfago: modelo experimental em camundongos (dissertação). São Paulo: Escola Paulista de Medicina, 1992.

12. Sallet JA, Andreollo NA, Venco FE, Brandalise NA, Leonardi LS. Carcinoma epidermóide de esôfago induzido pela dietilnitrosamina (DEN). Acta Cir Bras. 1996; 11(3):13843.

13. Sallet JA, Zilberstein B, Andreollo NA, Eshkenazy R, Pajecki D. Experimental esophageal carcinogenesis: technical standardization and results. Dis Esophagus. 2002; 15(4):278-81.

14. Velho AV, Kruel CDP. A influência do chá preto sobre a gênese tumoral esofágica induzida pela dietilnitrosamina: modelo experimental em camundongos (Dissertação). Rio Grande do Sul: Universidade Federal do Rio Grande do Sul, 1998.

15. Rubio CA, Liu F, Chejfec G, Sveander M. The induction of esophageal tumors in mice: dose and time dependency. In Vivo. 1983;1(1):35-8.
16. Li ZG, Shimada Y, Sato F, Maeda M, Itami A, Kaganoi J, Komoto I, Kawabe A, Imamura M. Promotion effects of hot water on Nnitrosomethylbenzylamine-induced esophageal tumorigenesis in F344 rats. Oncology Rep. 2003; 10(2):421-6.

17. Kruel CDP, Gurski r, Cavazzola LT, Kruel CRP, Madruga G, Sfair JA. Hot-water effect in the esophageal carcinogenesis experimental model in mice. In: Sixty World Congress of International Society for Diseases of the Esophagus, Milan, Italy. Abstract 1995. p.199.

Como citar este artigo:

Castro Júnior MAM, Kruel CDP, Meure L, Castro AP, Zimmermann BS. Modelo experimental de carcinogênese esofágica. Rev Col Bras Cir. [periódico na Internet]. 2007;34(3). Disponível em URL: http:/ /www.scielo.br/rcbc

Endereço para correspondência:

Miguel Angelo Martins de Castro Junior

Rua Visconde de Paranaguá 272

Bairro Centro

96200-190 - Rio Grande - RS

Tel: (053) 3232-8988 